BULLETIN Bulletin hispanique

HispaniquE Université Michel de Montaigne Bordeaux

120-1 | 2018

Varia

\title{
Las traducciones catalanas de Jean-Paul Sartre
}

Catalan translations of Jean-Paul Sartre

Las traducciones catalanas de Jean-Paul Sartre

Pilar Godayol

(2) OpenEdition

Journals

Edición electrónica

URL: https://journals.openedition.org/bulletinhispanique/6143

DOI: 10.4000/bulletinhispanique.6143

ISSN: 1775-3821

Editor

Presses universitaires de Bordeaux

Edición impresa

Fecha de publicación: 30 junio 2018

Paginación: 309-324

ISBN: 979-10-300-0298-0

ISSN: 0007-4640

Referencia electrónica

Pilar Godayol, «Las traducciones catalanas de Jean-Paul Sartre», Bulletin hispanique [En línea], 120-1 |

2018, Publicado el 01 enero 2022, consultado el 08 enero 2022. URL: http://journals.openedition.org/ bulletinhispanique/6143 ; DOI: https://doi.org/10.4000/bulletinhispanique.6143

Tous droits réservés 


\title{
Las traducciones catalanas de Jean-Paul Sartre ${ }^{1}$
}

\author{
PILAR GODAYOL \\ Universitat de Vic-Universitat Central de Catalunya
}

Après plus de vingt ans d'absence totale de traductions d'ouvrages étrangers, c'est en catalan que Jean-Paul Sartre arrive pour la première fois en Espagne, dans les années soixante. Cet article rend compte de l'accueil de Jean-Paul Sartre en catalan, pendant et depuis la dictature franquiste jusqu'à nos jours.

Mots-clés: histoire de la traduction, traduction catalane, existentialisme, censure, Jean-Paul Sartre.

Después de más de veinte ańos de ausencia de traducciones de obras extranjeras, Jean-Paul Sartre llegaba en los años sesenta por primera vez a España en catalán. Este artículo da cuenta de la recepción al catalán de Jean-Paul Sartre durante y después de la dictadura franquista, hasta nuestros días.

Palabras Clave: historia de la traducción, traducción catalana, censura, existencialismo, Jean-Paul Sartre.

After more than twenty years during which no translations of foreign texts were permitted in Spain, the work of Jean-Paul Sartre came forth, under the form of a translation into Catalan. This article deals with the translations into Catalan of Jean-Paul Sartre during and after the Franco dictatorship, up to the present day

Keywords: history of translation, Catalan translation, existentialism, censorship, Jean-Paul Sartre.

1. Este artículo se enmarca en las actividades del grupo de investigación consolidado «Grupo de Estudios de Género: Traducción, Literatura, Historia y Comunicación» (2014 SGR 62) de la Universitat de Vic-Universitat Central de Catalunya (UVic-UCC) y en el proyecto «Traducción y censura : género e ideología (1939-2000)» (Ref. FFI2014-52989-C2-2-P). ORCIC de la autora: 0000-0003-2513-5334. Correo electrónico: pgodayol@uvic.cat.

Bulletin Hispanique, Tome 120, n 1 - juin 2018 - p. 309-324. 


\section{INTROdUCción: ¿Por Qué JeAn-PAul SARTRE en CATALÁN?}

La victoria franquista en España asfixió durante años la actividad editorial del país. A partir de 1938, cualquier escrito tuvo que franquear el trámite de la censura previa. Respaldados por leyes y normativas, los censores de la administración controlaron completamente los medios de comunicación social. Libros, periódicos, revistas y folletos fueron objeto de inspección permanente. Sin embargo, durante las dos primeras décadas de la dictadura un hecho diferencial muy destacable aconteció entre el libro en castellano y el libro en las otras lenguas españolas: el acoso del primero fue parcial (títulos no afines al régimen), mientras que el del segundo fue total y demoledor al sumársele la censura lingüística. En esta época las traducciones al catalán, al gallego y al vasco estuvieron totalmente vetadas.

A partir de 1962 el nuevo ministro de Información y Turismo, Manuel Fraga Iribarne, revisó los criterios para la publicación de libros en España y abrió las puertas a las traducciones a las distintas lenguas. No se trató de una apertura total, pero sí de una cierta «liberalización» de la censura. En 1966 se aprobó la Ley de Prensa e Imprenta, la llamada Ley Fraga, que invalidó la de 1938. Se pasó de la "censura previa obligatoria» de los originales a la "consulta voluntaria», una censura encubierta que fue válida hasta 1976 y, en casos concretos, hasta $1978^{2}$.

Después de décadas de sequía de traducciones de obras extranjeras, durante los últimos años de la dictadura franquista la industria editorial catalana vivió una etapa de gran dinamismo, que se caracterizó por la variedad temática y la abundancia de títulos. Francesc Vallverdú aporta datos específicos: durante la etapa 1962-68, de la producción total de libros en catalán, que sumó 2.831 ejemplares, se editaron más de mil traducciones, «un rècord històrio» (2013: 13). En siete años, la traducción ocupó más del $38 \%$ de la producción global, porcentaje altísimo comparado con otros países. El momento culminante fue en 1965, cuando un 55\% del total fueron traducciones: "proporció excesiva que no es donava en cap altre lloc del món» (2013: 13). En esos mismos años, en castellano las traducciones representaban entre el $20 \%$ y el $30 \%$ de la producción; en danés, el 20\%, y, en otras muchas lenguas, el $10 \%$.

En esta época excepcional de la historia de la traducción catalana, aparecieron, "amb un desordre $i$ un retard inevitables en bona part», según Ricard Torrents (1969: 7), las siete primeras traducciones al catalán de Jean-Paul Sartre (véase, entre otros, los estudios sobre la recepción de Sartre en España de Díaz, 1983; Roviró, García-Duran, Sarrate, 2005). ¿Cómo se explica este interés por la obra de Jean-Paul Sartre en este momento? ¿O por las obras de Simone de

2. Para conocer la política censora sobre la traducción durante el franquismo en Cataluña, se pueden consultar, entre otros, los estudios de Cisquella et al. (1977), Abellán (1980), Vallverdú (1987, 2004, 2013), Gallén (1985), Gallofré (1991), Llanas (2006, 2007), Cornellà-Detrell (2010, 2016) y Bacardí (2012). 
Beauvoir, Albert Camus, Albert Gramsci, Franz Kafka, Karl Marx, Herbert Marcuse o Bertrand Russell?

En 2004, en "Testimonis de repressió i censura», en la monografía Franquisme i repressió editada por Pelai Pagès, Francesc Vallverdú explicaba una anécdota protagonizada por un periodista anónimo del periódico Le Figaro que revela el enigma. Resulta que el corresponsal francés llegó a afirmar que «la censura tractava amb més rigor les traduccions al castellà que no pas les traduccions al català» y que "en català es trobaven traduccions de Marx, Sartre, Gramsci, que no existien en castellà» (2004: 186). Doce años más tarde, Jordi Cornellà-Detrell (2016: 100-102) revisa cómo trató la prensa francesa este momento prodigioso de la traducción catalana y aporta más detalles sobre este sorprendente artículo, publicado el 16 de diciembre de 1965 en el semanario Le Figaro Littéraire, con el título "Malraux interdit à Madrid et publié à Barcelone». El reportero destacaba que los tirajes de algunos títulos, como las novelas de James Bond, eran idénticos en castellano y en catalán, y que esto se justificaba porque el nivel cultural en Cataluña era más elevado que en el resto de España. Además subrayaba que este boom editorial barcelonés había despertado la envidia de los editores madrileños que, por la censura gubernamental, habían perdido cuota de mercado internacional. El periodista se preguntaba por qué una lengua perseguida y maltratada gozaba de libertad para traducir, por ejemplo, La condition humaine, d'André Malraux, y La Nausée, de Jean-Paul Sartre, y, sorprendentemente, atribuía la contradicción al hecho de que el castellano fuera la lengua oficial del país. Cornellà-Detrell (2016: 106-108) incluye más crónicas sugestivas de la prensa francesa que reviven el fenómeno singular de la euforia editorial catalana. Destaca, por ejemplo, el artículo de Le Monde de julio de 1968, "Le raz de marée des lettres catalanes», de Mathilde y Albert Bensoussan, en que se sostenía que la edición catalana vivía un momento de verdadero renacimiento gracias a las traducciones.

A nivel cuantitativo, el periodista de Le Figaro Littéraire estaba en lo cierto: en la década de los sesenta algunos autores relevantes contemporáneos eran traducidos antes al catalán que al castellano. Lo que no comenta el redactor es que estos autores, prohibidos desde siempre por el franquismo en España, habían sido traducidos en América Latina porque los editores no tenían competidores editoriales y habían comprado los derechos de reproducción al español. Como el de Beauvoir (Godayol, 2013a, 2015, 2017), el caso de JeanPaul Sartre es un ejemplo de esta paradoja. A pesar de los múltiples ataques de la censura institucional, las siete traducciones al catalán de Sartre de estos años fueron las primeras en obtener la valoración positiva del aparato censor del Ministerio de Información y Turismo (MIT) y, por lo tanto, las primeras en llegar a España legalmente.

Cabe destacar que todas las obras que se trasladaron entonces al catalán ya estaban traducidas al español argentino (y algunas, con los mismos originales, circulaban clandestinamente por la Península). Concretamente tres editoriales de Buenos Aires compraron los derechos y las editaron a partir de los años 
cuarenta: Losada publicó La náusea en 1947, Baudelaire en 1949, Teatro en 1950, Critica de la razón dialéctica en 1963 y Las palabras en 1964; la Universidad Nacional de Córdoba, Esbozo de una teoría de las emociones en 1959; y Sur, Reflexiones sobre la cuestión judia en 1960. Además de parecer desconocer la política editorial expansiva de algunos países de América Latina, el periodista también desatendió el hecho de que algunos autores, entre ellos Sartre, se habían posicionado contra el régimen autoritario de Franco y se habían negado a vender los derechos a empresas editoriales españolas. Josep Maria Corredor, traductor de Els mots (1965), recordaba, en un artículo al periódico Avui del 27 de abril de 1980, con motivo de la muerte del autor francés, el compromiso intelectual de Sartre ante las imposiciones dictatoriales y su adscripción a las singularidades nacionales como la vasca o la catalana:

L'autor de Les mains sales tenia prohibit que a la Peninsula Ibèrica sortissin traduccions de les seves obres mentre subsistissin les dictadures portuguesa i espanyola. Amb tot, a causa de les prohibicions de què era victima la llengua catalana, a l'últim consentí que es publiquessin diverses traduccions a Barcelona. (Corredor, 1980: 3)

Prueba de ello es también el prefacio, "Sobre la lluita nacional basca», que Sartre escribió para Le procès de Burgos (1971), de Giselle Halimi, publicado en catalán (El procés de Burgos) por Edicions Esquerra Catalana dels Treballadors (E.C.T.), de Perpiñán, en 1973, en versión de Lluís Creixell, fuera de la supervisión censora franquista. En este texto Sartre defendía a los dieciséis vascos juzgados por el tribunal militar de Burgos y reconocía la validez de la lucha del pueblo vasco por la independencia y el socialismo. En una nota, el editor agradecía a la autora, Giselle Halimi, y a la editorial Gallimard haber autorizado la traducción «sense condicions» (1973: iv).

En resumen, Jean-Paul Sartre llegó por primera vez a España en catalán y se convirtió en uno de los autores franceses más traducidos en los últimos años de la dictadura franquista. De las quince traducciones existentes de Sartre publicadas al catalán en forma de libro (hay algunas traducciones de textos breves editadas en revistas académicas), siete pertenecen a esta primera época, fruto de un contexto histórico y social que alimentó el interés por su obra política y filosófica. A partir de entonces, las traducciones de Sartre llegaron gradualmente a Cataluña, concentrándose en fechas conmemorativas del autor (con motivo de su fallecimiento, al cumplirse los diez años de él y en la celebración del centenario de su nacimiento).

\section{Primera ETAPA: EL ATERRIZAJE FRONDOSO}

Publicadas entre 1965 y 1973, las siete primeras traducciones de Sartre responden al afán editorial de introducir nuevas ideas y autores en un momento en que la dictadura necesitaba dar una nueva imagen tanto en clave interna como externa. En ocho años se editaron los siguientes títulos, por orden de aparición: en noviembre de 1965, Aymà publicó Els mots (Les mots, 1964), en traducción de Josep M. Corredor, y, en 1966, La nàusea (La Nausée, 1938), de la 
mano de Ramon Xuriguera -quien, paralelamente, tradujo el primer libro que apareció de Simone de Beauvoir al catalán, Una mort molt dolça (Une mort très douce, 1964; Godayol, 2013b)-; en abril de 1967, Nova Terra editó Reflexions sobre la questió jueva (Réflexions sur la question juive, 1946), en traducción de Ramon Folch i Camarasa; en 1968, bajo el título Teatre, Aymà reunió seis piezas dramáticas del autor-Les mosques (Les mouches, 1943), A porta tancada (Huis-Clos, 1944), La p... respectuosa (La putain respectueuse, 1946) Morts sense sepultura (Morts sans sépulture, 1946), Les mans brutes (Les mains sales, 1948) y Les troianes (Les troyennes, 1965)-, traducidas por Manuel de Pedrolo; en abril de 1969, Edicions 62 publicó Esbós d'una teoria de les emocions (Esquisse d'une théorie des émotions, 1939), en traducción de Miquel Adrover, y, el mismo mes, Anagrama, Baudelaire (Baudelaire, 1947), en traducción de Bonaventura Vallespinosa; y, en junio 1973, Edicions 62 difundió Qüestions de mètode (Questions de méthode, 1957), en traducción de Carme Vilaginés.

En el Archivo General de la Administración del Estado (AGA), en Alcalá de Henares, se pueden consultar los ocho expedientes de censura de las solicitudes de traducciones catalanas de Jean-Paul Sartre, siete de las cuales se autorizaron y publicaron. En 1964 Aymà solicitó al MIT la autorización para traducir El mur, que le fue denegada. Hay que tener en cuenta que el orden de las fechas de inicio de los expedientes administrativos para obtener las autorizaciones no se corresponde con el orden final de las fechas de publicación, porque se retuvieron, se sometieron a tachaduras o incluso se desautorizaron. Para conocer cómo actuó la censura franquista ante las traducciones de Sartre al catalán, quiénes fueron los censores que redactaron sus expedientes, qué sostuvieron, qué tipo de cambios aplicaron a los textos y, en general, cómo castigaron al autor (por ateo y filocomunista), véase «Censorship and the Catalan translations of Jean-Paul Sartre» (Godayol, 2016a).

De los ocho títulos solicitados al MIT, cuatro fueron a iniciativa de Aymà, dos de Edicions 62, uno de Nova Terra y uno de Anagrama. Concretamente, Edicions 62 y Nova Terra, consideradas editoriales sospechosas por el régimen franquista por publicar sobre todo en catalán y obras "contestatarias» (Llanas 2006: 26 y 30), tuvieron que solicitar siempre una autorización antes de empezar la producción de la traducción, a diferencia de otras editoriales que, después de 1966, solamente depositaban seis ejemplares impresos del libro en los organismos censores para su autorización. A pesar de los ataques directos o indirectos del régimen franquista, los editores no desistieron. En cuanto a la importación de literatura extranjera, el propósito era claro: recuperar clásicos de todos los tiempos y difundir las ideas de los autores contemporáneos marcadamente ideológicos. Josep Maria Castellet, director literario de Edicions 62 desde 1964 hasta 1996, recordaba que cada título original y traducido «tenia una càrrega política $i$ ideològica» (Miralles 2012: 8).

Aún bajo los efectos de la controversia que originó la no aceptación de Sartre del premio Nobel de literatura de 1964, Proa publicó Els mots en noviembre de 1965. Fue la primera traducción catalana de Sartre. Josep M. Corredor (Girona 
1912 - Perpinyà, 1981) fue el prologuista y traductor. Ensayista y profesor universitario, Corredor se exilió en 1939 y residió en Perpiñán. Traductor al castellano de algunas piezas de André Gide, publicadas en Buenos Aires en 1952, en 1965 aceptó el encargo de Aymà para traducir la autobiografía de la infancia y la adolescencia de Sartre. En el prólogo, se aprecia que el traductor admiraba al autor francés: «Sartre és, sense cap mena de dubte, un dels escriptors més discutits, però més influents i més importants, de la nostra generació» (1965: 8).

La traducción de Corredor fue objeto de una larga polémica. Montserrat Bacardí reproduce todos los documentos del debate en La traducció catalana sota el franquisme (2012: 226-230). Inicialmente, Corredor escribió una carta dirigida al director de Serra d'Or, en la cual se quejaba de que no había podido revisar las pruebas de la traducción y denunciaba la mala práctica del corrector de la editorial: "Amb molta tristesa - i amb molta indignació, no cal amagar-hohaig de fer saber als lectors catalans que ha sortit una traducció del llibre Les Mots, de J.-P. Sartre, que no és la "meva", baldament porti el "meu nom" (1966: 9). A continuación, Aymà publicó, en la misma revista, la respuesta, lamentando la reacción de Corredor y defendiendo el hecho de "corregir en major o menor mesura» (1966: 9) las traducciones de autores de prestigio. Más tarde, un prestigioso grupo de "graduats en diverses universitats franceses" firmaban un comunicado a favor de Corredor y apoyando su traducción: "Els sotasignants... han pogut apreciar la fidelitat d'aquesta traducció en el seu conjunt» (Barrera et al. 1966: 5). En 2005, en el centenario del nacimiento de Sartre, Proa reeditó Els mots, en la misma traducción de cuarenta años atrás. Críticos literarios como Jordi Llovet elogiaban el trabajo de Corredor: "...en una prosa que, reblant la molt concisa $i$ ben periòdica de Sartre, resulta una senzilla meravella» (2005: 5).

Pocos meses después, en 1966, Proa, editó La nàusea, la primera novela del autor francés, en versión de Ramon Xuriguera, que también redactó el prólogo. En plena controversia por la traducción de Els mots, "La nàusea catalana va fer certa forolla» (Bacardí 2008: 71). Fue uno de los libros más leídos del momento. En una carta del 25 de noviembre de 1965, Joan Baptista Cendrós, propietario de Proa, revelaba a Josep Caralt que «després de moltes gestions hem pogut aconseguir el permís per editar La Nausée» (Vall 1990: 56). También corroboraba que Le mur había sido denegada por el MIT. Xuriguera abría el prólogo subrayando que "La incorporació de J. P. Sartre és un fet cabdal per a les lletres catalanes» (1966: 5). Lo atribuía a dos razones: porque "l'obra triada és essencial en la producció de l'auton» y por "la considerable influència que ha exercit i continua exercint en la literatura contemporània» (1966: 5). Admirador infatigable del autor, lo calificaba "d'escriptor excepcional» (1966: 10). Después de reseguir su trayectoria, resumía su fundamento ideológico: "des del moment que existim, som responsables» (1966: 9), y se adhiere a su filosofía de la función del escritor: "acordar a l'actualitat una atenció preferent» (1966: 9).

Entre los distintos ensayos que escribió Xuriguera, destaca La idea de l'home en la novel.la francesa (1961). En poco más de cien páginas, hacía un recorrido por la historia de este motivo. En el penúltimo capítulo, se adentraba 
en la novela existencialista y hacía hincapié en algunos de sus representantes, en un sentido muy amplio del término, desde Simone de Beauvoir, Albert Camus, Fiodor Dostoievski, Karl Jaspers y Frank Kafka hasta Gabriel Marcel y Emmanuel Mounier. Obviamente, Sartre era el hilo conductor y el escritor más elogiado. A lo largo del ensayo no dejaba de referirse a él como «l'autor de La Nausée» (1961: 111) y, de esta manera, preconizaba cuál sería su aportación traductora cinco años más tarde.

En abril de 1967, casi veinte años después de su publicación en París, Nova Terra editaba en Barcelona Reflexions sobre la questió jueva, en traducción de Ramon Folch i Camarasa (Barcelona, 1926). Traductor prolífico, Folch i Camarasa vivió en esta época de la traducción, trabajando, mayoritariamente, para Nova Terra y Edicions 62. Entre 1959 y 1969, trasladó alrededor de cien títulos de autores relevantes, clásicos y contemporáneos, como Agatha Christie, Colette, Charles Dickens, William Faulkner, Graham Greene, Ernest Hemingway, Aldous Huxley, Karl Marx, Carson McCullers, Bertrand Russell y Georges Simenon. Libro breve, sin introducción alguna, se incluyó en la colección divulgativa "Síntesi» de Nova Terra, editorial fundada en 1958 por un grupo de religiosos y laicos con "l'esperit solidari i col-lectiu del cristianisme social i progressista de l'època» (Llanas, 2006: 116).

En 1968, Aymà publicó el volumen Teatre, seis piezas dramáticas de Sartre: Les mosques, A porta tancada, La p... respectuosa, Morts sense sepultura, Les mans brutes y Les troianes. Poco después, Les mosques se representó en Barcelona por primera vez en catalán, el 8 de marzo de 1969 (Gallén, 1985). Manuel de Pedrolo (l'Aranyó, 1918 - Barcelona, 1990) fue el traductor. Prolífico narrador, poeta, dramaturgo y traductor, el teatro de Sartre fue una de sus escasas traducciones vocacionales. El ensayista y crítico teatral Xavier Fàbregas redactó el prólogo. En él, de entrada, analizaba la figura del intelectual, «aquest nou tipus humà, pensador professional aureolat de taumaturg» (1968: 5), y afirmaba que Sartre es su representante más ilustre, "capaç de sensibilitzar-se $i$ de fer-nos sensibilitzar sobre qualsevol afer sorgit en un punt del planeta $i$ en el qual hagi estat posada en qüestió la condició humana» (1968: 5). Después de repasar las teorías existencialistas aplicadas al teatro (Camus, Gabriel Marcel, etc.), Fàbregas entraba en el teatro sartreano, "compromès, un teatre rotundament polític» (1968: 8), a la vez que resumía las condiciones en que se estrenaron algunas de sus obras en París, especialmente Les mosques, que se presentó durante la ocupación nazi. Dedicaba las últimas palabras del prólogo a elogiar la traducción de Pedrolo: "Una part, la més considerable, del seu teatre, la tenim a l'abast en la traducció exacta i a la vegada rica que ha efectuat Manuel de Pedrolo, un dels nostres millors dramaturgs» (1968: 9).

En abril de 1969, Edicions 62 publicaba Esbós d'una teoria de les emocions, y, Anagrama, Baudelaire. Aparecido el original en 1939, Esquisse d'une théorie des émotions, fue traducido al catalán por Miquel Adrover (Campos, Mallorca, 1947). Arquitecto y escritor, Adrover fue un traductor prolífico del francés entre 1966 y 1970 y entre 1975 y 1977, mientras cursaba sus estudios. Trasladó 
más de cincuenta obras, en régimen de semiprofesional. En parte ello explica que este libro no contenga ningún tipo de texto introductorio. Por otro lado, Baudelaire, publicado originalmente en 1947, fue traducido por Bonaventura Vallespinosa (Vilafranca del Penedès, 1899 - Reus, 1987). Escritor y médico, compaginó el ejercicio de la medicina con la traducción, mayoritariamente de teatro, con el objetivo de que se representara en Reus, en el Centro de Lectura, de donde era el presidente de la Sección de Letras. La versión de Vallespinosa del Baudelaire de Sartre va acompañada de una presentación del filólogo y ensayista Ricard Torrents. Admirador de Sartre, lo introduce «com un dels primers pensadors de la nostra centúria» (1969: 8), que los mantiene vivos y actuales. Por lo que se refiere a Baudelaire, «constitueix una petita peça essencial, situada no a la periferia sinó al centre de l'existencialisme i el pensament sartrians" (1969: 9). Para Torrents, con este ensayo, Sartre no quiso «envair els terrenys del critic literari», ni "adoptar els aires de l'amateur que ocasionalment s'ocupa de la poesia», lo que realmente le interesaba era "l'home més que no el poeta», "el destí tràgic del poeta maleït per excel-lència» (1969: 9). Baudelaire constituye un ejemplo práctico de una de las tesis sartreanas de la libertad: "la tria lliure que l'home fa de si mateix sidentifica absolutament amb allò que anomenem destì" (1969: 10).

En junio de 1973 se cerró la primera época de traducciones catalanas de Sartre con Qüestions de mètode, obra publicada en la emblemática colección de ensayo "Llibres a l'Abast», de Edicions 62. Firmaba la versión Carme Vilaginés (Barcelona, 1935). Su esposo, el escritor Francesc Vallverdú, era entonces jefe de redacción de Edicions 62. Psicóloga clínica y escritora, Vilaginés, entre 1965 y 1973, combinó la traducción de algunas novelas de Marguerite Duras y Georges Simenon con la del ensayo filosófico de Simone de Beauvoir y de Jean-Paul Sartre. Vilaginés fue, en 1968, la traductora del segundo volumen de El segon sexe de Simone de Beauvoir (el primero fue a cargo de Herminia Grau). Mercè Rius, en la introducción a Defensa dels intel-lectuals (2006), de Sartre, recurre a la traducción catalana de Qüestions de mètode y revalora la obra porque en ella el filósofo integra el existencialismo dentro del marxismo.

En julio de 1968 el crítico literario Joan Triadú escribió un artículo de balance en Serra d'Or, «Després d'una generació sense traduccions», en que justificaba el boom traductor de los sesenta por el hecho de que era indispensable recuperar con rapidez «una generación sin novela traducida» (1968: 39). Aunque afirmaba que todavía eran insuficientes, elogiaba el hecho de que, en pocos años, habían aparecido más de un centenar de títulos «a cargo de escritores competentes, a menudo, o de buenos traductores" (1968: 39). Josep M. Corredor, Ramon Xuriguera, Ramon Folch i Camarasa, Manuel de Pedrolo, Miquel Adrover, Bonaventura Vallespinosa y Carme Vilaginés (Bacardí y Godayol, 2011), los traductores catalanes de Sartre de esta época, responden a la categorización de Triadú. La mayoría fueron escritores insignes de la literatura catalana, un perfil recurrente durante unos años en los que, con la «liberalización» de la censura 
franquista, gran parte de la intelectualidad compaginaba las dos tareas, por razones económicas, por responsabilidad histórica o por el mero hecho de que aún no existían los traductores «profesionales».

\section{SEgunda ETAPA: LOS TÍMIDOS RESURgIMIENTOS}

En plena transición democrática, a raíz de la muerte del autor francés, en 1980, Proa editó la colección de relatos con los que Sartre se había dado a conocer en 1937, El mur (Le mur, 1939), en traducción de Agustí Bartra (Barcelona, 1908 - Terrassa, 1982). Aymà había intentado publicar El mur en 1964, sin éxito. Poeta, narrador y dramaturgo, Bartra empezó a publicar durante la Guerra Civil y pronto tuvo que emigrar a Francia, donde conoció a la escritora Anna Murià. Juntos se exiliaron a la República Dominicana, Cuba y México, donde residieron hasta 1970. Durante sus treinta ańos de exilio se ganaron la vida con la traducción. Ya en Cataluña, en una entrevista con Feliu Formosa, poco antes de salir a luz la traducción, Bartra calificaba a Sartre como "un dels grans esperits del nostre segle» (1979: 13), "un dialèctic mundial, una profunda consciencia critica d'Europa» (1979: 14), a la vez que se identificaba con él «en la mesura de l'angoixa, de la lluita per a l'home auroral, de la creació $i$ de l'esperança, en ell sovint una esperança desesperada, però tanmateix esperança» (1979: 14). En la nota preliminar a El mur, Bartra presentaba al autor y su obra. De nuevo observaba que Sartre fue un "pensador actiu», que combatió todo tipo de opresión e injusticia, "naturalment comprès el franquisme» (1980: 5). Reportaba un dato paradigmático:

El 1966 donà un text autògraf per a la subasta que se celebrà a París i amb el producte de la qual foren pagades les multes imposades per les autoritats franquistes als intel.lectuals catalans que intervingueren en l'acte de constitució d'un Sindicat d'Estudiants, celebrat al convent dels Caputxins, a Barcelona. (1980: 5-6)

A propósito de su fallecimiento, el 16 de abril de 1980, la prensa catalana recordó a Jean-Paul Sartre con nostalgia y agradecimiento. Uno de sus discípulos, Josep Maria Castellet, lo evocaba como «Sartre o el gran emmerdadon", porque había cometido uno de los pecados más antiguos, "que és el d'emmerdar la nostra obra amb la politica» (1980: 68), y como "l'intel-lectual més obscè de tots els seus contemporanis», porque fue el que enseñó más claramente «les vergonyes dels seus dubtes, de les seves certeses arriscades $i$ de les seves contradiccions, tot $i$ teoritzantles sota la fórmula del "compromis"» (1980: 11). Aunque ya en noviembre de 1949, con veintitrés años, Castellet había publicado en la revista barcelonesa Estilo un artículo en el que se refería a la littérature engagée de Sartre, no fue hasta finales de 1950 cuando el intelectual francés entró en su vida, a partir de la lectura de la traducción argentina ¿Qué es la literatura? Castellet incorporó muchas de las ideas sartrianas en sus propuestas intelectuales. Una nuclear: "assumir la fidelitat al temps present $i$ la defensa d'aquell tipus de literatura que millor expliqui, exigeixi o demani aquest present» (Broch, 1996: 43). Castellet fue uno de los promotores de Sartre en Cataluña y España durante y después 
de la dictadura franquista (entre otros, Van Lawick, 1988; Broch, 1996; Vall, 2000). A partir de 1964, desde su posición de director literario de Edicions 62, fue el impulsor de algunas de las traducciones al catalán de Sartre y de la mayoría de las de Simone de Beauvoir (Godayol, 2016b, 2017).

Otra prosélita sartreana fue la escritora Maria Aurèlia Capmany (Barcelona, 1918-1991), quien, homenajeándolo a raíz de su muerte, lo definió como "nostre maitre à penser", "d'aquells pocs escriptors en el món que són molt més que la seva obra» (1980: 68). En 1982, la editorial Laia, en la colección de referencia «Textos Filosòfics», publicó la antología Fenomenologia i existencialisme, editada y traducida por Capmany, que incorpora una cronología, una introducción y una bibliografía exhaustivas (Bacardí y Godayol, 2013: 38-41). Licenciada en Filosofía y Letras por la Universidad de Barcelona y fiel seguidora del existencialismo francés, Capmany seleccionó cinco ensayos, mayoritariamente del «primer Sartre»: «L'existentialisme est un humanisme» (1968), «Husserl» (1969), «La liberté cartésienne» (1947), «Une idée fondamentale de la phénoménologie de Husserl: l'intentionnalité» (1947) y "La transcendance de l'Ego" (1972). En la introducción, Capmany trazaba un recorrido biobibliográfico del escritor y lo describía como «un home de frontera», «amb la barreja de sinceritat i teatralitat que el caracteritzarà sempre» (1982: 17). También manifestaba su interés, por una parte, por hacer llegar la obra de Sartre a un público relativamente amplio y, por la otra, por contribuir a la normalización del lenguaje filosófico catalán. Si Sartre se convirtió en uno de los filósofos más influyentes en la obra de Capmany, Simone de Beauvoir fue su gran cómplice. Cuando el MIT autorizó la traducción catalana de El segon sexe (1968), Castellet encargó el prólogo a Capmany (Godayol, 2017).

Entre la traducción de Maria Aurèlia Capmany, de 1982, y la siguiente, de Carme Serrallonga, en 1983 el poeta, traductor y editor Jordi Cornudella traducía, para la revista Els Marges, el famoso texto "Pourquoi écrire?» ("Per què escriure?»), que forma parte del ensayo "Qu'est-ce que la littérature?», publicado per primera vez en 1948 en la revista Les Temps modernes, fundada y dirigida por el mismo autor.

En 1985, Edhasa publicó Kean. Adaptació de l'obra d'Alexandre Dumas (Kean, 1954), en traducción de la pedagoga y traductora Carme Serrallonga (Barcelona, 1909-1997), que también lo prologó. Profesora y mujer de teatro, conocedora de varios idiomas, trasladó más de veinte obras del teatro universal, así como verdaderos hitos de la literatura alemana, francesa e italiana. Al final de su vida tradujo más de cincuenta títulos de literatura infantil y juvenil. Con afán didáctico, el prólogo de Kean se divide en tres partes: un recorrido biográfico del protagonista de la obra, el actor inglés Edmond Kean; la versión que hizo Alexandre Dumas de su vida, y la comparación de la versión de Dumas con la de Sartre. Para Serrallonga, a Sartre le atrajo Kean por partida doble: porque "va veure en el personatge més coses de les que Dumas havia intuït» y porque «a diferencia de quasi tots els altres herois romàntics acaba bé» (1985: viii). Serrallonga definía la obra como un «divertimento» (1985: viii) del pensador, 
que "agafa la comèdia amable, superficial, de Dumas i la torna a escriure» (1985: viii). Serrallonga amaba el teatro y Kean le ofreció la oportunidad de reescribir una obra intertextual por antonomasia.

El Institut del Teatre de Barcelona publicó en 1993 Un teatre de situacions (Un théâtre de situations, 1973), recopilación de prácticamente todos los textos sartreanos sobre el teatro. La versión catalana fue editada y presentada por Michel Contat y Michel Rybalka, y traducida por Jaume Melendres (Martorell, 1941 - Manresa, 2009). Melendres se dedicó al teatro desde todas sus facetas: director, traductor, crítico, profesor y autor de artículos y monografías sobre esta materia. Tradujo del francés, inglés, alemán e italiano; de Sartre, Un teatre de situacions, volumen que reunía dos de sus pasiones: el ensayo crítico teatral y la traducción. Michel Contat y Michel Rybalka dividen el libro en dos partes: por un lado, los escritos, las conferencias y las entrevistas sobre teatro en general; $y$, por el otro, textos diversos y entrevistas de circunstancias sobre las propias dramaturgias. En la introducción, Contat y Rybalka consideran a Sartre como "l'hereu de la important aventura teatral francesa entre les dues guerres» (1993: 12) y, su teatro, un clásico que «ja pertany a la historia literària contemporània» (1993: 9).

En 1996, la Universidad de Lleida y Pagès Editors publicaron Limaginari. Psicologia fenomenologica de la imaginació (L'Imaginaire. Psychologie phénoménologique de l'imagination, 1940), en edición y traducción de Nathalie Bittoun-Debruyne, que también se encargó de la introducción. Doctora en Filología Francesa, Bittoun-Debruyne ha trasladado al catalán grandes autores franceses, como Guy de Maupassant, Molière y Jules Verne. También ha traducido al francés poetas catalanes como Antoni Clapés, Francesc Parcerisas, Josep M. Sala-Valldaura y Víctor Sunyol. Tres años antes de aparecer su versión de Sartre, dio a conocer el libro Per un teatre de situacions, un útil recorrido pedagógico por el teatro sartreano. Sus conclusiones eran elocuentes: «Per a Jean-Paul Sartre, el teatre era, per damunt de tot, una forma de comunicar amb el públic, i totes les seves idees que s'hi relacionen van orientades cap a una millora formal i estètica d'aquesta finalitat. Un teatre d'acció: acció sobre l'escenari, acció sobre el públic, acció sobre el món» (1989: 65-66).

En 1999 Edicions 62 imprimió L'ésser $i$ el no-res. Assaig d'ontologia fenomenológica (L'être et le néant. Essai d’ontologie phénoménologique, 1943), en versión de la profesora universitaria de filosofía Mercè Rius, autora también de la introducción. En el centenario del nacimiento de Sartre, en 2005, Rius publicó la monografía De vuelta a Sartre, en la que llevaba a cabo una lectura personal de su obra, como uno de los pensadores más relevantes del siglo XX. No volvía a Sartre para actualizarlo, sino que se proponía revisarlo y, por consiguiente, abandonar algunos de los tópicos sobre su obra que han hecho fortuna. Para Rius el existencialismo sartreano nos brinda una filosofía de la conciencia que, sin prescindir en absoluto de sus condicionantes psicológicos y biológicos, defiende la libertad del individuo por encima de todo. Asimismo, en 2008, salió a la luz otro ensayo de Rius sobre Sartre, Tres assaigs sobre Sartre: 
i una conferencia més. Finalmente, en 2010, L'Harmattan de París le publicó Quatre essais sur Sartre, en traducción de Annie Bats.

Ya en el tercer milenio, en 2006, a partir de la efeméride del centenario de su nacimiento, se trasladaron al catalán dos de sus textos más políticos. Por una parte, Edicions El Jonc ofreció Paisatge d'un segle, una selección de artículos de los diez volúmenes de Situations, dedicados a las más diversas cuestiones políticas de su época. La edición y la traducción fueron a cargo del doctor en historia Ramon Usall y de la traductora Elena Garsaball. Con el título «Sartre XX», el prólogo de Usall y Garsaball reivindica la figura de Sartre como «l'home del segle» (2006: 9), etiqueta que le acuñó el filósofo francés Bernard-Henri Lévy. Según los editores, con su muerte, la obra filosófica, literaria y política de Sartre fue "condemnada a l'ostracisme i a l'oblit» (2006: 9), de modo que pretenden recuperar a Sartre para el público catalán y presentarlo como se merece: "un dels grans intel.lectuals del segle més apassionant de la historia de la humanitat, el segle XX» (2006: 10). Además, ello permite hacer balance de los grandes acontecimientos ocurridos a lo largo del siglo a través "dels ulls $i$ la ploma de Jean-Paul Sartre» (2006: 10). Con sus artículos y entrevistas, revisamos desde la guerra mundial contra el fascismo, la guerra fría, el colonialismo, los nacionalismos y el Mayo de 1968 hasta la emergencia de naciones sin estado en Europa y el conflicto árabe-israelí. La historia de Sartre y la historia del siglo XX son "paral-leles», «indestriables» (2006: 10). Cabe destacar que el último ensayo de esta antología es "El procés de Burgos», una retraducción del prefacio que Sartre escribió para el libro de Giselle Halimi, Le procès de Burgos (1971), en el que denunciaba el régimen fascista español y se posicionaba abiertamente a favor de los militantes de ETA procesados en Burgos.

Por otra parte, en 2006, la Universidad de Valencia editó Defensa dels intel.lectuals (Plaidoyer pour les intellectuels, 1972), en versión de Albert Mestres y con un prólogo de Mercè Rius. Escritor, traductor y director de escena, Albert Mestres es profesor del Institut del Teatre de Barcelona y ha publicado poesía, textos dramáticos, narrativa y ensayo. Ha traducido clásicos como el Marqués de Sade, Fernando Pessoa y Jean Racine. La introducción de Rius constituye un paseo por el pensamiento sartreano. Defensa dels intel.lectuals consta de tres conferencias complementarias, pero autónomas, en progresión dialéctica, que Sartre impartió en Tokio y Kioto, en su viaje a Japón en otoño de 1965: «¿Qué es un intelectual?», «Función del intelectual» $\mathrm{y}$ «¿Es un intelectual un escritor?». Expone Rius que la primera trampa del libro radica en el título, que no anuncia ninguna alabanza, ni tan siquiera una justificación moral perentoria; todo lo contrario: a la manera de Kierkegaard, para Sartre «defensar és desaconsellar» (2006: 11). En este ensayo Sartre reivindica su derecho a existir, "contra el pronòstic de "la mort dels intel.lectuals" llançat des dels Estats Units» (2006: 11). Como apunta Rius al final de la introducción, Sartre "s'aferrava al seu no-lloc, cohabitant amb l'impossible» (2006: 25).

Ya en 2009, la Revista catalana de filosofía publicaba la traducción de "Visages», texto filosófico, fenomenológico, en muchos sentidos precursor, aparecido en la revista Verbe (no 4-5) en 1939, poco después de La Nausée y 
el mismo año que Le Mur. El traductor, Xavier Garcia-Duran, asevera que el breve ensayo, con "innegable valor literari», muestra "un Sartre que juga amb els mots creant imatges no sempre precises en l'espectador. Per això, el text sembla a voltes oscil.lant, a voltes indecis» (2009: 5). Es en este sentido que Garcia-Duran prefiere «el punt $i$ seguit» que «el punt $i$ coma» del autor.

Finalmente, Jordi Llovet, en la reseña «Ficar-se on no us demanen», publicada en El País, el 29 de junio de 2006, lamentaba que en la bella edición de Defensa dels intel.lectuals no se incluyera la página, una sola, que el mismo Sartre escribió para la edición de 1965 de estas conferencias, en la cual "començava molt bé el seu plaidoyer definint els intel.lectuals com aquella mena de persones que "es fiquen on no els demanen" (2006: 5). Llovet asevera que esta fue "la constant del seu ofici» (2006: 5) y que la ilusión por cambiar el mundo, en tanto que filósofo engagé, le honora.

\section{CONCLUSIONES: «FICAR-SE ON NO US DEMANEN»}

El título de la reseña de Jordi Llovet, haciéndose eco de las palabras de Sartre, no debería justificar el muro de silencio y olvido al que fue condenado el escritor después de su muerte. Usall y Garsaball aducen este ostracismo a la incomodidad del personaje: "el compromís que en vida havia mantingut li passà factura» (2006: 9). En la celebración del centenario de su nacimiento, Octavi Martí apuntaba en El País, el 18 de junio de 2005, que los mismos franceses no sabían qué hacer con el autor:

Comunista, fumador, bebedor, adicto al Corydane, Sartre es irrepetible. Nadie se atreve a hacérselo suyo, ningún partido ni bando le quiere porque el tipo y su obra son mucho más ricos que nuestro actual pensamiento débil y consensual, y el uno y la otra están atravesados por más contradicciones de las que ningún heredero es capaz de asumir. (2005: 3-4)

A pesar de caer en un cierto abandono en el mundo cultural europeo del tercer milenio, Jean-Paul Sartre no es un intelectual olvidado en el contexto catalán: se sigue traduciendo más o menos puntualmente. En una situación de bonanza editorial (aunque bajo un férreo control político), en los años sesenta se trasladaron abundantemente todo tipo de obras sartreanas: filosofía, teatro y narrativa. A partir de 1973 se produjo una parada hasta 1980, en que, con motivo de la muerte del autor, se reanudaron las traducciones, con El mur. Desde entonces, no ha transcurrido ningún decenio sin que se tradujese alguna de sus obras al catalán. Las últimas obras traducidas son a iniciativa de investigadores universitarios, cuyo interés redunda en el Sartre filósofo e ideólogo. Con el objetivo de mantener su perspicaz presencia viva, lo reconocen como una voz clave del legado humanístico del siglo XX, que debe ser incorporada, ya sea para aplaudir o glorificar, ya sea para contradecir o rechazar. En unos tiempos algo desalentadores para el pensamiento de las letras, Sartre nos emplaza y nos pide que "ens fiquem on no ens demanen", a su manera, sin reparo, con compromiso. 


\section{Referencias bibliográficas}

Abellán Manuel L., 1980, Censura y creación literaria en España (1939-1976), Barcelona, Península.

Bacardí Montserrat, 2008, «Ramon Xuriguera i la traducció». URC. Revista Literaria, $\mathrm{n}^{\circ} 23,66-71$.

- La traducció catalana sota el franquisme, 2012, Lleida, Punctum.

Bacardí Montserrat, Godayol Pilar (eds.), Diccionari de la traducció catalana, Vic, Eumo Editorial, 2011.

Bacardí Montserrat, Godayol Pilar, 2013, Les traductores i la tradició. 20 pròlegs del segle $X X$, Lleida, Punctum.

Bartra Agustí, 1979, El gos geomètric, Barcelona, Laia.

Bittoun-Debruyne Nathalie, 1989, Jean-Paul Sartre: per un teatre de situacions, Barcelona, Institut del Teatre.

Broch Àlex, 1996, «Un intel.lectual sartreà», en Homenatge a J. M. Castellet, Barcelona, Edicions, 62, 41-45.

Capmany Maria Aurèlia, mayo 1980, «Sartre fora dels seus llibres», Saber, I, no 3, p. 68.

Castellet Josep Maria, 16 abril 1980, «El gran emmerdador», Saber, I, nº 3, mayo 1980, p. 68-69.

— «L'intel-lectual més obscè», Avui, p. 11.

Cisquella Georgina et al., 1977, La represión cultural en el franquismo. Diez años de censura de libros durante la Ley de Prensa (1966-1976), Barcelona, Anagrama.

Cornellà-Detrell Jordi, 2010, "Traducció i censura en la represa cultural dels anys 1960", L'Avenç no 359, , 44-51.

— "El terratrèmol de les lletres catalanes": traducció, censura i mercat del llibre en català als anys 60», 2016, en Traducció $i$ censura en el franquisme, Laura Vilardell (ed.), Barcelona, Publicacions de l'Abadia de Montserrat, 97-126.

Corredor Josep M., 27 de abril 1980, «Comiat a Jean-Paul Sartre», Avui, p. 3.

Díaz Carlos, 1983, «Los españoles y Sartre: crónica de un retraso», Arbor, no 114, 448, 452-462.

Gallén Enric, 1985, El teatre a la ciutat de Barcelona durant el règim franquista (19391954), Barcelona, Institut del Teatre / Edicions 62.

Gallofré M. Josepa, 1991, L'edició catalana i la censura franquista (1939-1951), Barcelona, Publicacions de l'Abadia de Montserrat.

Godayol Pilar, 2013a, "Censure, féminisme et traduction: Le Deuxième sexe de Simone de Beauvoir en catalan", Nouvelles Questions Féministes, no 32, 2, 74-88.

— «Simone de Beauvoir en català», 2013b, Bulletin Hispanique, no 115, 2, 669-684.

— «Simone de Beauvoir bajo la censura franquista: las traducciones al catalán», 2015, Quaderns de filologia. Estudis literaris, no 20, 17-34.

— «Censorship and the Catalan translations of Jean-Paul Sartre», 2016a, Perspectives. Studies in Translatology, no 24, 1, 59-75. 
— "Josep Maria Castellet, editor de autoras feministas traducidas», 2016b, Trans. Revista de Traductología, no 20, 87-100.

- Tres escritoras censuradas. Simone de Beauvoir, Betty Friedan y Mary McCarthy, 2017, Granada, Comares.

Halimi Giselle, 1971, Le procès de Burgos, París, Gallimard.

Lawick Heike van, 1988, «Heike van Lawick entrevista Josep Maria Castellet», Daina, 5, 7-23.

Le Figaro, 1965, «Malraux interdit à Madrid et publié à Barcelona», Le Figaro Littéraire, 16 diciembre 1965.

Llanas Manuel, 2006, L'edició a Catalunya: el segle XX (1939-1975), Barcelona, Gremi d'Editors de Catalunya.

- L'edició a Catalunya: el segle XX (els darrers trenta anys), 2007, Barcelona, Gremi d'Editors de Catalunya.

Llovet Jordi, 13 octubre 2005, «Autobiografies lletrades», Avui, p. 5.

— «Ficar-se on no us demanen», 20 junio 2006, El País. Quadern, p. 5.

Martí Octavi, 18 junio 2005, «Francia no sabe qué hacer con Sartre», El País. Babelia, 3-4.

Miralles Mercè, 20-26 abril 2012, "Mig segle de llibres», Presència, 4-10.

Rius Mercè, 2005, De vuelta a Sartre, Barcelona, Crítica.

- Tres assaigs sobre Sartre: i una conferencia més, 2008, Palma, Lleonard Muntaner.

- Quatre essais sur Sartre, 2010, Paris, L'Harmattan [Trad. Annie Bats].

Roviró Ignasi, García-Duran Xavier, Sarrate Carlos, 2005, «El impacto de Sartre en España, Concordia. International Journal of Philosophy, no 48, 77-102.

Sopena Mireia, «Le franquisme contre la pensée. L'essai français sous la surveillance de la censure franquiste», Pandora. Revue d'Études Hispaniques, no 6, 2007, 243-256.

Triadú Joan, 1968, «Després d'una generació sense traduccions», Serra d’Or, no 106, marzo 1968, 39-41.

Vall Xavier, 1990, La literatura catalana de postguerra i l'existencialisme (1945-1968), Tesi doctoral, Barcelona, Universitat Autònoma de Barcelona, 56-57.

Vall Xavier, 2000, "Josep Maria Castellet i 'l'existencialisme’", Els Marges, no 66, 7-23. Vallverdú Francesc, 1987, Edicions 62. Vint-i-cinc anys (1962-1987), Barcelona: Proa.

— "Testimonis de repressió i censura», 2004, en Franquisme i repressió. La repressió franquista als Països Catalans (1939-1975), Pelai Pagès i Blanch (ed.), València, Universitat de València, 81-187.

— «La traducció i la censura franquista: la meva experiència a Edicions 62», 2013, Quaderns. Revista de Traducció, no 20, 9-16.

Xuriguera Ramon, 1961, La idea de l'home en la novel.la francesa, Barcelona, Rafael Dalmau.

\section{Traducciones de Jean-Paul Sartre al catalán}

Sartre Jean-Paul, 1965, Els mots, Barcelona, Aymà [Prólogo y traducción de Josep M. Corredor].

— La nàusea, 1966, Barcelona, Aymà [Prólogo y traducción de Ramon Xuriguera]. 
- Reflexions sobre la questió jueva, 1967, Barcelona, Nova Terra [Traducción de Ramon Floch i Camarasa].

- Teatre (A porta tancada. Les mosques. Les mans brutes. Morts sense sepulture. Les troianes), 1968, Barcelona, Aymà [Prólogo de Xavier Fàbregas y traducción de Manuel de Pedrolo].

- Esbós d'una teoria de les emocions, 1969, Barcelona, Edicions 62 [Traducción de Miquel Adrover].

- Baudelaire, 1969, Barcelona, Anagrama [Prólogo de Ricard Torrents y traducción de Bonaventura Vallespinosa].

— Qüestions de mètode, 1973, Barcelona, Edicions 62 [Traducción de Carme Vilaginés].

— «Sobre la lluita nacional basca», 1973, en El procés de Burgos, Giselle Halimi, Perpinyà, Edicions Esquerra Catalana dels Treballadors (E.C.T.) [Traducción de Lluís Creixell].

- El mur, 1980, Barcelona, Proa [Nota preliminar y traducción de Agustí Bartra].

- Fenomenologia i existencialisme, 1982, Barcelona, Edicions 62 [Prólogo, edición y traducción de Maria Aurèlia Capmany].

— «Per què escriure?», 1983, Els Marges, no 27-28-29, 109-121 [Traducció de Jordi Cornudella].

- Kean: adaptació de l'obra d'Alexandre Dumas, 1985, Barcelona, EDHASA [Prólogo y traducción de Carme Serrallonga].

- Un teatre de situacions, 1993, Barcelona, Institut del Teatre [Prólogo y edición de Michel Contat y Michel Rybalka y traducción de Jaume Melendres].

- L'imaginari. Psicologia fenomenològica de la imaginació, 1996, Lleida, Universitat de Lleida / Pagès [Prólogo, edición y traducción de Nathalie Bittoun-Debruyne].

- L'ésser i el no-res. Assaig d'ontologia fenomenologica: selecció, 1999, Barcelona, Edicions 62, [Prólogo y traducción de Mercè Rius].

- Paisatge d'un segle, 2006, Lleida, El Jonc [Prólogo, edición y traducción de Ramon Usall y Elena Garsaball].

- Defensa dels intel.lectuals, 2006, Valencia, Universitat de València [Prólogo y traducción de Albert Mestres].

— «Rostres», 2009, Revista catalana de filosofía, no 11, 2, 5-10 [Traducció de Xavier Garcia-Duran]. 